\title{
Blurring the Paradigmatic Edges: Navigating the Boundaries Between Critical-Interpretive and Interpretive Approaches to Health Communication Research
}

\begin{abstract}
Anne Kerber*
Department of Communication Studies, College of Arts and Humanities, Minnesota State University Mankato, Mankato, MN, United States

Critical-interpretive health communication $(\mathrm{CHC})$ scholars take seriously the imperative to "take an ethical position" on communicative phenomenon, specifically identifying both issues of power as well as opportunities to catalyze social change (Zoller and Kline, 2008, p.93). Yet, researchers are also likely to encounter competing impulses to understand or even appreciate others' lived experiences in line with interpretive health communication $(\mathrm{IHC})$ practices. My perspective essay traces the blurry edges between $\mathrm{ClHC}$ and $\mathrm{HC}$, and offers guidance to researchers who traverse these borders. Specifically, I articulate the key points of convergence and divergence between $\mathrm{CIHC}$ and IHC perspectives, and consider the questions and implications accompanying these approaches.
\end{abstract}

Keywords: critical health communication, interpretive health communication, social change, research methods, paradigmatic boundaries

\section{INTRODUCTION}

\author{
"Simon says touch your nose! Now, touch your toes!" \\ "Oooh - You're out! You're out!"
}

A raucous group of second-graders pointed and laughed as I made my way to the sidelines. "I was never any good at 'Simon Says'!' I smiled at a cluster of adult volunteers offering sympathetic chuckles. There were far worse ways to conduct fieldwork, I thought. It was a warm and sunny October morning in rural Ohio. At least 75 children, parents, grandparents and caregivers, volunteers, and one friendly Labrador retriever had converged on a small town's community park for their school's first-ever "Walk-To-School Day."

The event would appear effortlessly successful to an outsider. I knew otherwise, as a member of the school wellness committee that had planned it. I had been observing the committee's meetings for my dissertation, interested in the communicative organizing of school-based health initiatives and drawn to members' passion for improving students' well-being amid challenging circumstances. The school was situated in an economically disadvantaged region known for intractable poverty, and disproportionately high rates of diabetes, heart disease, obesity, and substance abuse. My burgeoning interests in critical-interpretive health communication (CIHC) primed me to reflect on how the committee's efforts to address health disparities were constrained by a lack of material resources (e.g., funding, dedicated time, staffing, community infrastructure), and mired in power and structural issues at the national, state, and local levels (e.g., legislative mandates, inequalities in municipal and school funding). 
When finding a safe sidewalk that linked directly to school proved insurmountable, the committee instead arranged for students to walk to a local park where they were picked up by buses. I felt torn between my CIHC sensibilities and my newfound appreciation of the committee's improvisational organizing as I processed the event. Did my project's critical focus limit my ability to foreground such moments? Should I instead approach my research from an interpretive health communication (IHC) standpoint? Would taking both stances toward my data be wishy-washy (at best), or (at worst) a betrayal of methodological and epistemological imperatives?

\section{ENCOUNTERING AND ENGAGING THE PARADIGMATIC EDGES}

Questions about what is gained or lost by embracing a particular methodological perspective continue to permeate my scholarship. CIHC has usefully informed my interrogations of the ideologies underpinning school-based health initiatives (e.g., Gerbensky-Kerber, 2011; Gerbensky-Kerber and Bates, 2015). However, I also am drawn to IHC in moments where I want to foreground non-critical theories (Kerber and Murphy, 2018) or highlight creativity, innovation, and incremental social change. The desire to blur the "paradigmatic edges" is not unique, nor is it exclusive to health communication (Denzin, 2010; Tracy, 2013, p. 47; Moore and Manning, 2019). Communicative phenomena present multiple facets for scholars to critique, describe, and appreciate. Clear delineations between published works utilizing CIHC and IHC are often difficult to tease out, as both investigate communication within marginalized populations and/or address issues of power, structure, and agency. The deductive writing methods and traditional monograph structures favored by many high-impact journals further obscure analytic and theory-building processes characterizing CIHC and IHC approaches (Tracy, 2012).

My perspective essay draws upon personal experiences and existing literature to trace the blurry edges between CIHC and IHC. It may seem odd to use a critical health communication forum to foreground its intersections with IHC. Yet, delineating firm paradigmatic borders ignores their socially constructed nature (Lynch and Zoller, 2015), and obscures how "researchers may productively draw from multiple, seemingly contradictory perspectives" (Moore and Manning, 2019, p. 6). For scholars seeking to traverse the $\mathrm{CIHC} / \mathrm{IHC}$ boundaries, it is important to fully understand the key points of convergence and divergence between these approaches, and consider the questions and implications accompanying methodological choices.

\section{POINTS OF CONVERGENCE AND DIVERGENCE}

CIHC and IHC's close associations make sense, given important points of theoretical and methodological convergence. Ontologically, both IHC and CIHC foreground the intersubjective nature of meaning-making (Zoller and Kline, 2008). Both perspectives investigate how socially constructed understandings of health emerge from local realities, and acknowledge how knowledge claims reflect scholars' personal and theoretical standpoints, and methodological practices (Mumby, 2000; Lindlof and Taylor, 2002). My dissertation fieldwork, for example, focused on investigating the committee's relationships between "discourses-in-use (text, daily talk, and interaction) and larger social discourses (knowledge formations)" (Zoller and Dutta, 2008, p. 450). Regardless of which perspective I employed, it was essential for me to be reflexive about what my positionality (White, cis-gendered, middle-class woman) and theoretical sensibilities (narrative, feminist) primed me to notice during committee meetings and the Walk-to-School Day event.

The divergence between CIHC and IHC perspectives begins with their views on theory's role in research. Interpretive scholars traditionally begin the inquiry process with a theoretical openness toward their data, engaging in iterative movements between communicative phenomena and existing theory to develop interpretations (Tracy, 2013). CIHC scholars begin research with an explicit commitment to interrogating the operations of power, and are primed to explore related issues (e.g., agency, voice, representation, resistance) in data (Lupton, 1994; Lawless and Chen, 2019). The distinction has important implications: Whereas, IHC views health experiences as social products, $\mathrm{CIHC}$ researchers view the same experiences as "products of social systems and ideological processes" (Lupton, 1994, p. 58).

Research on celebrity health narratives further illustrates these differences. Beck et al. (2014) engaged an IHC perspective to argue celebrities' disclosure of personal health issues educate and inspire audiences, and influence activism. Despite using similar research methods (qualitative thematic analysis) and shared conceptual resources (narrative theory), Bute et al.'s (2016) CIHC study noted audiences perceived some celebrity narratives as "privileged, unrealistic, and even insensitive to 'real' crises of illness and disease" (p. 1015). Both studies advance theorizing about celebrity health narratives, but reach markedly different conclusions about their implications for public understandings of illness based on their perspectives.

Social justice represents another area where CIHC and IHC perspectives both overlap and sharply diverge. Although a commitment to praxis has not traditionally been central to an IHC perspective, researchers have increasingly called for interpretive research that generates social action (see arguments by Denzin, 2010). In contrast, emancipation is at the core of a CIHC research ethic (Lupton, 1994; Dutta and Zoller, 2008). Thus, it isn't surprising that both CIHC and IHC approaches have been used to study marginalized populations, the lived impact of health policies and practices, and other issues concerning health equity. The use of community-based and participatory research methods, which aim to democratize scholarly processes for participants, has also proliferated in CIHC and IHC over the last decade (e.g., Harter et al., 2011; Najib Balbale et al., 2014; Rositch et al., 2019).

However, CIHC and IHC perspectives deviate regarding the methods for achieving social justice. Although interpretive approaches illustrate lived experiences of marginalization, critical voices directly challenge the established ideologies 
and discursive formations creating systems of oppression. Lupton (1994) argued that failing to address the role of power undermines the transformative potential of CIHC research. Zoller (2005) similarly questioned non-critical research positioning community-oriented health promotion as empowering simply because citizens assumed responsibility for health improvements. While noting the importance of community capacity-building, she contended that ignoring the inherently political nature of health activism risked "reinforcing the logic of neoliberal economic policies that undercuts the notion of health as a public good and support for social safety nets" (p. 359).

Complicating matters further, scholars also differ in their views of how "critical" research must be to remain consistent with a social justice ethic. Lawless and Chen (2019) noted ontological and epistemological differences in criticality exist within and outside of communication studies. A case in point: Moore and Manning (2019) implored researchers to view the distinctions between critical and interpretive scholarship along a continuum based on attention to issues of power. Yet, Pasque and Salazar Pérez (2015) contended that flexible interpretations of criticality have the potential to reify the same hierarchies scholars seek to problematize, and argued for stronger congruence across the inquiry process. Clearly, the blurry edges between CIHC and IHC approaches generate entanglements for researchers to consider regarding where and how to position their scholarship.

\section{QUESTIONS AND IMPLICATIONS}

In what follows, I draw from research exemplars and my own experiences to articulate key questions and implications for scholars to consider when navigating between CIHC and IHC impulses.

\section{Planning Research}

Reflexivity is essential as scholars prepare to embark on the research process. Key questions to ask should include: What are my political and/or ethical commitments as a scholar? How do my theoretical sensibilities influence my perspective on my intended research? An IHC approach such as appreciative inquiry might be appropriate for scholars seeking to foreground practices that "sustain and enhance life-giving potential" (Ludema et al., 2001, p. 189). Yet, an assets-based perspective may not be appropriate for CIHC scholars seeking to expose a phenomena's ideological and hegemonic features (Barge and Oliver, 2003). Engaging in reflexive practices empowers researchers to design research questions aligned with their identified commitments, and determine the appropriate methodological and theoretical tools for achieving intended outcomes.

Researchers should also weigh the potential impact of their CIHC/IHC commitments on participants. Although I was familiar to members of the school wellness committee when I started my dissertation, I was hesitant to share my CIHC sensibilities with them. If my critique led participants to become dispirited about their health organizing, the trust and relationships I had developed with them could be irreparably harmed (see Carragee and Frey, 2016). Sharing my perspectives led to some initially uncomfortable conversations, but participants were ultimately reassured that the committee's practices could be made more inclusive by my work.

\section{Collecting and Analyzing Data}

Researchers at the CIHC/IHC borders should also heed Ellingson's (2009) reminder to "listen to your data... Pay attention to those flashes of insight, and they will lead you to the heart of what you need to address" (p. 79). Remaining open to the discourses and lived experiences encountered during research is essential for identifying such impulses. Reflexive interpretation (Alvesson and Sköldberg, 2009) is another useful practice that encourages researchers to engage in ongoing selfreflection as they work with data, and can help to surface potential turning points or alternative avenues for exploration. My dissertation fieldwork, for example, initially sought to highlight the school health committee's communicative practices. Observing community engagement in the Walk-to-School event, and reflecting on committee members' problematic comments about families they served sparked a new direction: How did the committee's membership practices disincentivize parental participation? And, what was the cost of excluding community voices in the wellness committee's initiatives?

Other questions emerge when determining sensitizing concepts and methods for analyzing data. Manning and Denker (2015), for example, asked whether privileging critical sensibilities meant obscuring other potentially robust theoretical frameworks. The answer is no: CIHC researchers productively couple critical and interpretive concepts. For instance, the culture-centered approach draws from both structuration and subaltern theories to interrogate localized health meanings and address disparities for marginalized communities (Dutta, 2018; see also Dutta, 2008). Other CIHC scholars have invoked narrative, problematic integration, and embodiment theories (for exemplars, see Parsloe and Babrow, 2016; Ellingson and Borofka, 2018; Field-Springer and Margavio Striley, 2018). Drawing from other theoretical perspectives broadens a researcher's interpretive repertoire, empowering them to explore how concepts can be deployed in multiple ways, and acknowledge what both $\mathrm{CHC}$ and IHC offer for developing knowledge claims (Ellingson, 2009; Lynch and Zoller, 2015; Manning and Denker, 2015).

Additionally, researchers must ask how critically oriented their approach to data analysis will be, and evaluate the implications of their choices. CIHC research frequently employs interpretive approaches (e.g., thematic, narrative, or discourse analyses), albeit with a commitment to power relationships (Dutta and Zoller, 2008). Yet, scholars have expressed concerns such approaches have the potential to obscure the analytic processes that make a study critical, and called for the development of more explicitly critical methodologies (Pasque and Salazar Pérez, 2015; Lawless and Chen, 2019).

\section{Writing}

As they write, scholars must ask where it makes sense to offer critique and/or description, and reflect on the potential implications of their knowledge claims. Revisiting the initial goals outlined in the planning phases is an important step, particularly 
when coupled with additional reflexivity about how the research process has unfolded. Scholars should consider questions, such as: What do I hope to accomplish with this research? What are the most meaningful parts of my data? What are the practical and ethical implications of sharing these results?

Defining goals related to social change is also essential. Not only do advocacy levels vary among scholars, navigating between "ideal" standards of activism and what is realistically possible (given situational and material constraints) represents an enduring struggle (Carragee and Frey, 2016). Furthermore, researchers should consider where CIHC and IHC offer complementary perspectives for engaging in social justice work. IHC approaches are useful for highlighting efforts to flip the script of dominant discourses, and identify how the lessons of successful advocacy can be applied in other contexts. CIHC approaches can identify structural ironies or paradoxes that enable and constrain agency, unmask conceptual blind spots for creating more inclusive changes, or illuminate tensions embedded within unique or promising strategies. Harter's et al. (2008) ethnographic exploration of mobile health clinics demonstrated the importance of this model for delivering health care in under-resourced communities. However, they also simultaneously noted the structural shortcomings in health care systems that necessitate such organizing.

Clarity of purpose also illuminates the possibilities for disseminating research, both within and outside of the academy: Where might it be possible to blend methodological or theoretical boundaries, or is data more suited to single-genre research accounts? What is the potential for creating crystallized texts

\section{REFERENCES}

Alvesson, M., and Sköldberg, L. (2009). Reflexive Methodologies: New Vistas for Qualitative Research, 2nd Edn. London: Sage.

Barge, J. K., and Oliver, C. (2003). Working with appreciation in managerial practice. Acad. Manage. Rev. 28, 124-142. doi: 10.5465/amr.2003.8925244

Beck, C. S., Aubuchon, S. M., McKenna, T. P., Ruhl, S., and Simmons, N. (2014). Blurring personal health and public priorities: an analysis of celebrity health narratives in the public sphere. Health Commun. 29, 244-256. doi: 10.1080/10410236.2012.741668

Bute, J. J., Quinlan, M. M., and Quandt, L. K. (2016). Informing or exploiting? Public responses to Guiliana Rancic's health narrative. Health Commun. 31, 1008-1018. doi: 10.1080/10410236.2015.1027987

Carragee, K. M., and Frey, L. R. (2016). Communication activism research: engaged communication scholarship for social justice. Int. J. Commun. 10, 3975-3999. Retrieved from: https://ijoc.org/index.php/ijoc/article/view/6004/1750

Denzin,. N. K. (2010). The Qualitative Manifesto: A Call to Arms. Walnut Creek, CA: Left Coast Press.

Dutta, M. J. (2008). Communicating Health: A Culture-Centered Approach. London: Polity Press.

Dutta, M. J. (2018). Culture-centered approach in addressing health disparities: communication infrastructures for subaltern voices. Commun. Methods Meas. 12, 239-259. doi: 10.1080/19312458.2018.1453057

Dutta, M. J., and Zoller, H. M. (eds.). (2008). "Theoretical foundations: interpretive, critical, and cultural approaches to health communication," in Emerging Perspectives in Health Communication: Meaning, Culture, and Power (New York, NY: Routledge), 1-27.

Ellingson, L. L. (2009). Engaging Crystallization in Qualitative Research: An Introduction. Thousand Oaks, CA: Sage.

Ellingson, L. L., and Borofka, K. (2018). Long-term cancer survivors; everyday embodiment. Health Commun. 22, 1-12. doi: 10.1080/10410236.2018.1550470 that interweave multiple, aesthetic forms of expression to highlight the key moments and nuances in our data (Ellingson, 2009)? Recent health communication scholarship has further highlighted the success of using film, live performance, and podcasting to represent experiences (e.g., Harter et al., 2017). Thorough consideration of both traditional and new avenues for disseminating research may be useful for empowering scholars to achieve their intended goals.

\section{CONCLUSION}

Making sense of the blurry edges between CIHC and IHC approaches is important as these perspectives continue to expand. Identifying CIHC and ICH's commonalities and differences creates opportunities to enhance theoretical and methodological vocabularies, and respond to paradigmatic critiques leveled at these approaches (e.g., Lawless and Chen, 2019; Moore and Manning, 2019). The questions and implications discussed in this essay are by no means exhaustive. Rather, I hope they will spark a larger conversation about how health communication scholars can speak "within and across paradigms" to create "new spaces and ways of imagining health care” (Zoller and Dutta, 2008, p. 461).

\section{AUTHOR CONTRIBUTIONS}

The author confirms being the sole contributor of this work and has approved it for publication.

Field-Springer, K., and Margavio Striley, K. (2018). Managing meanings of embodied experiences theory: toward a discursive understanding of becoming healthier. Health Commun. 33, 700-709. doi: 10.1080/10410236.2017.1306413

Gerbensky-Kerber, A. (2011). Grading the "good" body: a poststructural feminist analysis of body mass index initiatives. Health Commun. 26, 354-365. doi: 10.1080/10410236.2010.551581

Gerbensky-Kerber, A., and Bates, B. R. (2015). "Freedom from fat is freedom to fight: a Foucauldian reading of mission: readiness' Too Fat to Fight report," in A Communicative Perspective on the Military: Interactions, Messages, and Discourses, eds E. Sahlstein Parcell and L. Webb (New York, NY: Peter Lang), 335-352.

Harter, L. M., Deardorff, K., Kenniston, P., Carmack, H., and Rattine-Flaherty, E. (2008). "Changing lanes and changing lives: the shifting scenes and continuity of care of a mobile health clinic," in Emerging Perspectives in Health Communication: Meaning, Culture, and Power, eds H. M. Zoller and M. J. Dutta (New York, NY: Routledge), 313-334.

Harter, L. M., Hamel-Lambert, J., and Millesen, J. L. (eds.). (2011). Participatory Partnerships for Social Action and Research. Dubuque, IA: Kendall Hunt.

Harter, L. M., Pangborn, S. M., Ivancic, S., and Quinlan, M. M. (2017). Storytelling and social activism in health organizing. Manag. Commun. Q. 31, 314-320. doi: 10.1177/0893318916688090

Kerber, A., and Murphy, M. (2018). 'He's a battler. He's not a quitter:' the narrative framing of Jerry Kill's health-related organizational exit. J. Appl. Commun. Res. 46, 703-722. doi: 10.1080/00909882.2018.1548029

Lawless, B., and Chen, Y. (2019). Developing a method of critical thematic analysis for qualitative communication inquiry. Howard J. Commun. 30, 92-106. doi: 10.1080/10646175.2018.1439423

Lindlof, T. R., and Taylor, B. C. (2002). Qualitative Communication Research Methods, 2nd Edn. Thousand Oaks, CA: Sage.

Ludema, J. D., Cooperrider, D. L., and Barrett, F. J. (2001). “Appreciative inquiry: the power of the unconditional positive question," in Handbook of Action 
Research: Participative Inquiry and Practice, eds P. Reason and H. Bradbury (Thousand Oaks, CA: Sage), 189-199.

Lupton, D. (1994). Toward the development of critical health communication praxis. Health Commun. 6, 55-67. doi: 10.1207/s15327027hc0601_4

Lynch, J. A., and Zoller, H. M. (2015). Recognizing differences and commonalities: the rhetoric of health and medicine and criticalinterpretive health communication. Commun. Q. 63, 498-503. doi: 10.1080/01463373.2015.1103592

Manning, J., and Denker, K. (2015). Doing feminist interpersonal communication research: a call for action, two methodological approaches, and theoretical potentials. Women Lang. 38, 133-142.

Moore, J., and Manning, J. (2019). What counts as critical interpersonal and family communication research? A review of an emerging field of inquiry. Ann. Int. Commun. Assoc. 43, 40-57. doi: 10.1080/23808985.2019. 1570825

Mumby, D. K. (2000). “Common ground from the critical perspective: overcoming binary oppositions," in Perspectives on Organizational Communication: Finding Common Ground, eds S. R. Corman and M. S. Poole (New York, NY: Guilford Press), 68-86.

Najib Balbale, S., Schwingel, A., Chodzko-Zajko, W., and Huhman, M. (2014). Visual and participatory research methods for the development of health messages for underserved populations. Health Commun. 29, 728-740. doi: 10.1080/10410236.2013.800442

Parsloe, S. M., and Babrow, A. S. (2016). Removal of Asperger's syndrome from the DSM V: community response to uncertainty. Health Commun. 31, 485-494. doi: 10.1080/10410236.2014.968828

Pasque, P. A., and Salazar Pérez, M. (2015). "Centering critical inquiry: methodologies that facilitate critical qualitative research," in Critical Qualitative Inquiry: Foundations and Futures, eds G. S. Cannella, M. Salazar Perez, and P. A. Pasque (New York, NY: Left Coast Press), 139-170.
Rositch, A. F., Atnafou, R., Krakow, M., and D’Souza, G. (2019). A communitybased qualitative assessment of knowledge, barriers, and promoters of communicating about family cancer history among African-Americans. Health Commun. 34, 1192-1201. doi: 10.1080/10410236.2018.1471335

Tracy, S. J. (2012). The toxic and mythical combination of a deductive writing logic for inductive qualitative research. Qual. Commun. Res. 1, 109-141. doi: 10.1525/qcr.2012.1.1.109

Tracy, S. J. (2013). Qualitative Research Methods: Collecting Evidence, Crafting Analysis, Communicating Impact. Malden, MA: Wiley-Blackwell.

Zoller, H. M. (2005). Health activism: communication theory and action for social change. Commun. Theory 15, 341-364. doi: 10.1111/j.1468-2885.2005.tb00339.x

Zoller, H. M., and Dutta, M. J. (eds.). (2008). "Emerging agendas in health communication and the challenge of multiple perspectives," in Emerging Perspectives in Health Communication: Meaning, Culture, and Power (New York, NY: Routledge), 449-463.

Zoller, H. M., and Kline, K. N. (2008). Theoretical contributions of interpretive and critical research in health communication. Ann. Int. Commun. Assoc. 32, 89-135. doi: 10.1080/23808985.2008.11679076

Conflict of Interest: The author declares that the research was conducted in the absence of any commercial or financial relationships that could be construed as a potential conflict of interest.

Copyright (c) 2019 Kerber. This is an open-access article distributed under the terms of the Creative Commons Attribution License (CC BY). The use, distribution or reproduction in other forums is permitted, provided the original author(s) and the copyright owner(s) are credited and that the original publication in this journal is cited, in accordance with accepted academic practice. No use, distribution or reproduction is permitted which does not comply with these terms. 